\title{
Assessment of historical polymers using attenuated total reflectance-Fourier transform infra-red spectroscopy with principal component analysis
}

Gemma Mitchell ${ }^{1}$, Fenella France ${ }^{2}$, Alison Nordon'1 ${ }^{1}$ Pik Leung Tang ${ }^{3}$ and Lorraine T Gibson ${ }^{1 *}$

\begin{abstract}
Introduction: Attenuated total reflectance-Fourier transform infrared (ATR-FTIR) spectroscopy with a diamond ATR crystal was used to examine 41 historical polymer fragments and a selection of polyurethane fragments subjected to accelerated ageing. The advantages and limitations of FTIR data for polymer assessment is discussed. Moreover the efficacy of the data interpretation tool principal component analysis (PCA) is debated for potential applications in polymer characterisation and polymer degradation.
\end{abstract}

Results: Analysis of polymer fragments by ATR-FTIR spectra was shown, as expected, to be an ideal method for polymer classification. Curved surfaces could be tolerated when spectral data were carefully collected, similarly opaque samples could be analysed due to the reflective nature of the FTIR technique used. More importantly perhaps, these results reaffirm the necessity to examine individual spectra as further information can be obtained which allow a better understanding of the material's stability. It was possible to identify potential degradation of cellulose nitrate and rubber, discriminate between the ether and ester-form of polyurethane, and discriminate between high and low density polyethylene. It was also shown that PCA could be used to unambiguously identify samples which contained cellulose acetate, cellulose nitrate, polycarbonate or polyurethane with a selection of known samples, but without the use of a spectral library.

Conclusions: This study supports previous publication results indicating that ATR-FTIR is a useful tool for the examination of objects containing polymers. Here it was shown that polymers could be characterised in object fragments that were not specially prepared and without the use of a spectral library. PCA was shown to be a useful tool for the unambiguous identification of cellulose acetate, cellulose nitrate, polycarbonate or polyurethane polymers in historical plastics with different additives, plasticisers or age. More excitingly, even though spectral features were similar for new and aged samples of polyurethane, PCA was able to discriminate between samples of foam that had been treated by heat $\left(50^{\circ} \mathrm{C}\right.$ for $24 \mathrm{~h}$ or $\left.144 \mathrm{~h}\right)$ or by exposure to light, although more results for other polymeric materials are required to support this proof of concept study.

Keywords: ATR-FTIR, Plastics, Heritage collections, Degradation, Principal component analysis

\footnotetext{
* Correspondence: Lorraine.gibson@strath.ac.uk

'Department of Pure and Applied Chemistry, WestCHEM, University of

Strathclyde, Glasgow G1 1XL, UK

Full list of author information is available at the end of the article
} 


\section{Introduction}

Objects that contain synthetic, complex and inherently unstable modern materials, particularly polymer-based materials, are becoming integral parts of heritage collections at ever increasing rates; reflecting both the growing use of these materials in modern society and an interest in their own artistic qualities and interpretation. Many synthetic polymers were sought after as they were made to imitate more expensive materials such as tortoiseshell $[1,2]$ and ivory $[1,3]$. Now polymers feature in museum collections in a wide variety of forms from packing materials and storage containers to sculpture, jewellery, toys and cinematic film. There are also many examples of natural plastic materials within heritage collections such as shellac, gutta percha and horn. Such materials were moulded and used for a variety of applications including buttons, brooches and liquid receptacles [4]. Unsurprisingly polymeric materials are present in almost all heritage collections across the world and represent a tribute to industrial, social or cultural progress.

As relatively recent additions to heritage collections these contemporary materials are less well studied and their chemical decomposition pathways have not yet been fully elucidated. Moreover, it is often difficult to determine the nature of the polymer used within an object making it difficult to determine appropriate storage conditions or assess an object's potential to degrade under the imposed environmental storage or display conditions. Deterioration of many thousands of polymer, or polymer-containing objects, is now becoming apparent and research questions regarding the durability of contemporary art objects need to be addressed. The concept of degradation and useful lifetime can often be indistinct. The polymer industry regard a polymer as being degraded when it loses a particular percentage of the object's original weight, at which stage the plastic is considered to have reached the end of its useful lifetime. In a heritage context the definition is not as well defined and objects often have to be considered on a case by case basis. With regards to heritage objects the term 'useful lifetime' can often be misunderstood. Objects are not necessarily 'in-use' in a traditional sense, but rather are on display or in storage. In general, most heritage institutions would regard an object as being at the end of its useful lifetime when it shows significant loss of quality or when the original meaning of the object is no longer perceivable. In addition, an object may be considered at the end of its lifetime when its degradation is causing an adverse impact on other collection items, at which point it will be removed from exhibition.

Previous museum surveys in the 1990's [5,6], provided a snapshot of polymer object condition at the time of monitoring. In a survey based at the British Museum, the number of polymer objects was so large $(>3000$ objects) that only a representative part of the collection was examined and visual signs of degradation and requirement for conservation work were noted together with the surrounding environmental conditions [6]. The types of polymers identified in the collection included cellulose acetate, Bakelite (phenol formaldehyde), cellulose nitrate, polyurethane, polypropylene, polyethylene, nylon, polystyrene, rubber and poly (vinyl chloride) (PVC). The results of the study highlighted that $27.5 \%$ of the collection required no treatment, $60 \%$ was deemed a low conservation priority and $12 \%$ required essential work. In addition, approximately $0.6 \%$ of the objects surveyed were in need of immediate conservation treatment; all of these contained PVC and were actively degrading and producing surface tackiness as a result of plasticiser migration. More recently, a survey was conducted in the furniture collection at the Victoria and Albert Museum as part of the Popart project [7]. The objects ranged in date from the 1930's to modern day and included historic plastics to modern recycled materials. Of the 200 objects surveyed $57 \%$ were found to be in good condition, 28\% were recorded to be in a fair state (interpreted as having minor damage such as discolouration), $12 \%$ were in a poor condition (physical damage was present with brittleness and sweating of objects being a possibility). Only $3 \%$ of the objects studied were classed as unacceptable and therefore chemically unstable; this time the most unstable objects contained polyurethane.

Deterioration of polymeric objects can manifest itself in many ways. Materials can change colour, become physically deformed and fragile or may break apart into hundreds of smaller pieces. An additional problem that should not be underestimated is that during the deterioration process volatile organic compounds (VOCs) are often emitted from the surface of the object as it degrades. These VOCs, if acidic, can further exacerbate the object's chemical decay pathway (e.g. inducing an autocatalytic degradation cycle) or it could induce the corrosion of metal or calcareous objects held in close proximity to the degrading polymer [8]. Cellulose acetate, cellulose nitrate and PVC are materials which are known to emit acetic acid, nitric acid or hydrochloric acids, respectively, during degradation [9-12]. For example, conservators at the British Museum were alerted to nitric acid emission from a cellulose nitrate shadow puppet when the tissue paper used to pack the puppet became increasingly yellow and brittle to the touch [13]. In addition, the metal rivets which held the puppet together were corroded and the legs of the puppet had become severely crazed. Tests identified the plastic as cellulose nitrate and found a $\mathrm{pH}$ gradient across the object with the legs being highly acidic ( $\mathrm{pH} 3.2 \pm 0.2)$ and the body less so (pH $5 \pm 0.2$ ). 
In this research study, 41 unknown polymer fragments were collected from standard reference materials (ResinKit ${ }^{\mathrm{TM}}$, Woonsocket, USA), industrial standards (supplied by the Scottish Plastic and Rubber Association, SPRA) and objects from private collections (see Table 1). The ability of ATR-FTIR spectroscopy to identify and classify polymers from such a wide range of sources, (with differing formulations, additives and plasticisers) was assessed. Samples were not modified prior to analysis and ranged in size from $1.3 \mathrm{~cm}^{2}$ to $10.6 \mathrm{~cm}^{2}$, each having an approximate mass of $100 \mathrm{mg}$. Classification was attempted based on a visual assessment of spectroscopic data after which the data was analysed by PCA. Knowing that the age of plastic materials ranges dramatically in heritage collections, 5 polyurethane fragments were also subjected to accelerated ageing and the collected spectral data were reassessed visually and using PCA to assess the utility of the spectroscopic method for the analysis of polymers in historical collections.

\section{Results and discussion}

\section{Polymer characterisation of $\mathbf{4 1}$ sample fragments}

The 41 sample fragments analysed in this study were of varying formulations, age, texture, topography, colour and shape. Nonetheless, identification of polymer type was possible without the need for sample preparation, such as solvent extraction. The use of a pressure clamp for solids was necessary to provide good contact between the sample and the diamond window used in the ATR-FTIR instrument. However, the force used to provide good contact with the crystal and the surface of the object created visual indentations on the more pliable materials such as PVC, polyethylene, polyurethane foams and rubber. It is possible to use spacers, which lessen the indentations on a measured sample by spreading the pressure over a larger area, however the use of spacers can make the analysis more cumbersome. Indentations were more pronounced on samples which were already in a degraded and vulnerable state. It is therefore suggested that analysis by ATR-FTIR using a pressure clamp for solids could be used on 'hard' polymer samples or, if possible, using fragments which have already fallen, or broken, from catalogued heritage objects. Otherwise small indentations will need to be tolerated during analysis and the sample area needs to be carefully selected. Difficulties were also experienced during the analysis of samples which had an unusual shape, for example, the analysis of a rounded dolls milk bottle was challenging. This polycarbonate sample had threading indentations for a screw cap and the unusual shape meant that it took some time to locate an area that gave good contact with the FTIR-ATR crystal. However it was still possible to collect spectroscopic data without further sample preparation such as using a microtome to provide a smooth surface.

The ATR-FTIR spectra were collected in replicate $(n=10)$ across the surface of the 41 polymer fragments. Collected spectroscopic data were examined to identify the main IR absorption bands and to classify the unknown polymer fragments; the results are given in Table 2 and compared with previously published results [14-26]. Not all users of ATR-FTIR possess a polymer sample library therefore representative spectra for each polymer type can be viewed within the additional information section in the online version of this paper (see Additional file 1, Additional file 2, Additional file 3, Additional file 4, Additional file 5, Additional file 6, Additional file 7, Additional file 8, Additional file 9). In addition, examination of individual spectra can provide the user with further interpretation that is not otherwise possible if, for example, spectral database matching was used rather than spectra interpretation. Examples are given below.

In the case of cellulose nitrate each sample analysed featured a peak at $1721 \mathrm{~cm}^{-1}$ that was attributed to a carbonyl stretch. The presence of a carbonyl containing plasticiser, such as camphor or phthalate ester, was ruled out as it was not possible to identify the other characteristic bands for camphor (2963 and $2874 \mathrm{~cm}^{-1}$ ) [27], or phthalate plasticiser (2861, 1579 and $1602 \mathrm{~cm}^{-1}$ ) [28,29]. It was therefore proposed that the carbonyl stretch indicated sample degradation and the intensity of this peak could potentially be used to indicate the state of degradation [25]. The spectra of polycarbonate samples had aromatic stretches at 1594, 1605, 1081, 1015 and $830 \mathrm{~cm}^{-1}$ suggesting an aromatic, rather than aliphatic, base structure, most likely bisphenol A. The spectra from rubber samples had additional peaks at 3350 and $1714 \mathrm{~cm}^{-1}$, which were attributed to an $\mathrm{OH}$ and carbonyl stretch. Nor and Ebdon [30] reported these peaks to be present in natural rubber samples which had been degraded by ozonolysis. It is therefore proposed that these peaks could again be used to provide an inferential measure of the state of degradation of rubber samples. The spectra of polyurethane samples HS 86, 458, 461 and 464 indicated these samples were produced using an ether polyol. This was confirmed by the absence of bands at 1187, 1128 and $1064 \mathrm{~cm}^{-1}$ which are attributed to the $\mathrm{C}-\mathrm{O}-\mathrm{C}$ bend of the ester polyol [22]. Moreover, sample HS 69 could be identified as a polyurethane elastomer with additional bands present at 2936, $1702_{\text {shoulder }} 1188,1162,1103,1065,1047$ and $730 \mathrm{~cm}^{-1}$. The bands at 1188 and $1065 \mathrm{~cm}^{-1}$ were attributed to the $\mathrm{C}-\mathrm{O}-\mathrm{C}$ bend of an ester polyol. Bands present at 1166 and $996 \mathrm{~cm}^{-1}$ in polypropylene spectra were indicative of the isotactic form of this material [31,32]. Furthermore, sample HS 416 had an absorption band at $1740 \mathrm{~cm}^{-1}$ 
Table 1 Polymers selected for analysis in this study

\begin{tabular}{|c|c|c|c|}
\hline Sample & Source & Object & Description \\
\hline \multicolumn{4}{|c|}{ Polystyrene } \\
\hline HS 36 & ResinKit $^{\mathrm{TM}}$ & & Colourless, transparent, rigid \\
\hline HS 38 & ResinKit $^{\mathrm{TM}}$ & & White, opaque, rigid \\
\hline HS 405 & Private collection & Stereo cassette player & White, opaque, rigid \\
\hline HS 409 & Private collection & Cassette tape & Grey, opaque, rigid \\
\hline HS 446 & SPRA & Moulded shape & Colourless, transparent, rigid \\
\hline \multicolumn{4}{|c|}{ Cellulose acetate } \\
\hline HS 91 & Private collection & Crumb brush & Pink, opaque, rigid \\
\hline HS 474 & Private collection & Thin film & Colourless, transparent \\
\hline HS 475 & Private collection & Thin film & Colourless, transparent \\
\hline HS 476 & Private collection & Thin film & Colourless, transparent \\
\hline HS 477 & Private collection & Thin film & Colourless, transparent \\
\hline \multicolumn{4}{|c|}{ Cellulose nitrate } \\
\hline HS 270 & Private collection & Comb & White, opaque, rigid \\
\hline HS 271 & Private collection & Cigarette case & Mock tortoiseshell, transparent, rigid \\
\hline HS 248 & Private collection & Ruler & Orange, transparent, rigid \\
\hline \multicolumn{4}{|c|}{ Polycarbonate } \\
\hline HS 52 & ResinKit $^{\mathrm{TM}}$ & & Colourless, transparent, rigid \\
\hline HS 143 & Private collection & Dolls milk bottle & Green, transparent, curved, rigid \\
\hline HS 413 & Private collection & Drinking glass & Colourless, transparent, curved, rigid \\
\hline HS 466 & SPRA & Moulded shape & Colourless, transparent, rigid \\
\hline HS 467 & SPRA & Raw polymer beads & Colourless, transparent, rigid \\
\hline \multicolumn{4}{|l|}{ Rubber } \\
\hline HS 268 & Private collection & Pipette bulb & Brown, opaque, cracked \\
\hline HS 269 & Private collection & Dolls head & Brown, opaque, cracked \\
\hline HS 103 & Private collection & Hot water bottle & Brown, opaque, pliable \\
\hline \multicolumn{4}{|l|}{ PVC } \\
\hline HS 62 & ResinKit $^{\mathrm{TM}}$ & & Colourless, transparent, rigid \\
\hline HS 415 & Private collection & Swim arm bands & Yellow, opaque, textured, pliable \\
\hline HS 424 & Private collection & Record & Black, opaque, ridged, pliable \\
\hline HS 430 & Private collection & Money wallet & Black, opaque, pliable \\
\hline HS 468 & SPRA & Moulded shape & Grey, opaque, rigid \\
\hline \multicolumn{4}{|c|}{ Polyurethane } \\
\hline HS69 & ResinKit $^{\mathrm{TM}}$ & & Colourless, transparent, elastomer \\
\hline HS 86 & Private collection & Packing material & White, foam \\
\hline HS 458 & SPRA & Packing material & Pink, antistatic foam \\
\hline HS 461 & SPRA & Packing material & Black, foam \\
\hline HS 464 & SPRA & Packing material & Grey, foam \\
\hline \multicolumn{4}{|c|}{ Polypropylene } \\
\hline HS 77 & ResinKit $^{\mathrm{TM}}$ & & White, opaque, rigid \\
\hline HS 400 & Private collection & Thermos $^{\oplus}$ flask & Black, opaque, rigid \\
\hline HS 403 & Private collection & Thermos $^{\circledast}$ flask cup & White, opaque, rigid \\
\hline HS 416 & Private collection & Tupperware ${ }^{\oplus}$ box & Brown, opaque, rigid \\
\hline HS 444 & SPRA & Moulded object & Colourless, semi-transparent, rigid \\
\hline
\end{tabular}


Table 1 Polymers selected for analysis in this study (Continued)

\begin{tabular}{|c|c|c|c|}
\hline \multicolumn{4}{|c|}{ Polyethylene } \\
\hline HS 80 & ResinKit $^{\mathrm{TM}}$ & & White, opaque, pliable \\
\hline HS 404 & Private collection & Scalextric crash barrier & White, opaque, pliable \\
\hline HS 417 & Private collection & Tupperware $^{\circledast}$ lid & Colourless, semi-transparent, pliable \\
\hline HS 459 & SPRA & Packing material & Black, crosslinked foam \\
\hline HS 463 & SPRA & Packing material & White, non-crosslinked foam \\
\hline
\end{tabular}

which was attributed to a carbonyl stretch present due to oxidative degradation of the sample. Polyethylene sample HS80 had an additional band present at $1378 \mathrm{~cm}^{-1}$, which was attributed to a $\mathrm{CH}_{3}$ bend and is indicative of low density polyethylene; which has a small amount of branching on the polymer chains. The band at $1378 \mathrm{~cm}^{-1}$ was not present in the other polyethylene samples (see Table 2) suggesting no branching in the polymer chains, indicating high density polyethylene.

\section{Principal component analysis of measurement data for 41 fragments}

Although the polymers present in all samples were successfully characterised here by visual examination of collected spectra, users can often rely on the use of spectral libraries for matching the spectra of unknown materials with stored data. It is common for commercial libraries to use spectra from new (pristine) samples. However, as a plastic sample ages the search algorithms may become less effective and matches will become poorer to the point where an incorrect match could be generated. Inhouse built libraries which contain a range of degraded sample spectra could overcome this potential problem, however not all users have such a facility. Therefore, spectral data was interrogated using principal component analysis to assess whether it could be used to unambiguously identify a polymer type in a sample regardless of its age, formulation or the presence of additives and plasticisers. The collected spectra $(n=10)$ of the 41 samples were exported into MatLab, derivatised, normalised and mean centred before principal component analysis (PCA) was used to assess sample correlations.

From the PCA results, the eigenvalue plot indicated that 10 principal components (PCs) could be used to describe $92 \%$ of the data variation, however the first 4 PCs showed specific sample types which tended to be distinct from the other samples. Examination of the scores plot for PC 1 (see Figure 1) indicated that most of the samples have scores values between -1.5 and 2, with samples of the same type having similar scores, e.g. all the polycarbonate samples have a PC1 score value of 1.5 to 1.75. However, the PC1 scores values observed for cellulose acetate $(-5.5$ to -2$)$ are clearly distinct (see triangles at the bottom right hand side of Figure 1) from those observed for the other 8 different polymer types, suggesting that $\mathrm{PC} 1$ can be used to discriminate cellulose acetate. The scores plots for PC2, PC3 and PC4 (see Figures 2, 3 and 4), demonstrated distinct scores values for polycarbonate samples (PC2 scores values between -4.2 and -5.6 ), polyurethane samples (PC3 scores values between -4.0 and -4.8 ) and cellulose nitrate samples (PC4 scores values between 4.0 and 4.5), respectively. Interestingly, the polyurethane elastomer (HS69-highlighted in Figure 3 with a red circle) did not fit into the grouping of polyurethane foams; this level of discrimination was not possible by examination of the original spectra. A range of scores values are observed for the 10 repeat measurements of individual samples owing to slight variations in the sample surface. An uneven sample surface can create poorer contact between the sample and the crystal window of the ATR-FTIR, which will lead to slight differences in the spectra. However, the variation was minor and did not affect the ability to unambiguously identify samples which contained cellulose acetate, polycarbonate, polyurethane and cellulose nitrate on the basis of their PC1, PC2, PC3 and PC4 scores, respectively. Where samples had a smooth and regular surface good surface contact resulted in less cluster variation (for example see Figure 4). Here it was necessary to have samples of known type to undertake the PCA analyses, however it is proposed that sample classification of unknowns would be possible with the use of clustering and discrimination tools.

\section{Examination of aged polyurethane samples}

A polyurethane foam sample was cut $(n=5)$ and used as a case study to assess the use of ATR-FTIR to discriminate between 'fresh' and 'aged' polyurethane samples. The 5 sections of foam were placed in a Weather-Ometer and subjected to the conditions given in Table 3. After ageing the measured original replicate spectra for all 5 samples (PU1 - PU5) were examined visually and although some spectral differences were observed it was not possible to clearly distinguish between the replicate spectra $(n=10)$ collected for the unaged sample (PU1) or samples aged for $24 \mathrm{~h}$ in the dark (PU2), $24 \mathrm{~h}$ in the light (PU3), 144 $\mathrm{h}$ in the dark (PU4) or 144 $\mathrm{h}$ in the light 
Table 2 Main ATR-FTIR absorption bands

\section{Polymer}

Polystyrene (HS 36, 38, 405, 409 \& 446)

Cellulose acetate (HS 91, 474, 475, 476 \& 477)

Cellulose nitrate (HS 248, 270 \& 271)

Polycarbonate (HS 52, 143, 413, 466 \& 467)

Rubber (HS 103, 268 \& 269)

Poly(vinyl chloride) (HS 62, 415, 424, 430 \& 468)

Polyurethane (HS 69, 86, 458, 461 \& 464)
Main IR absorption bands $\left(\mathrm{cm}^{-1}\right)$

$3025(\mathrm{C}-\mathrm{H})$ stretch

2921 \& $2854\left(\mathrm{CH}_{2}\right)$ asymmetric \& symmetric stretch

1602 ring stretch

$1449(C=C)$ ring

$905(\mathrm{C}=\mathrm{CH})$

$745 \& 696(\mathrm{C}-\mathrm{H})$ bend of aromatic ring

2977 \& $2932\left(\mathrm{CH}_{3}\right)$ asymmetric \& symmetric stretch

2951 \& $2880\left(\mathrm{CH}_{2}\right)$ asymmetric \& symmetric stretch

$1740(C=0)$

$1367\left(\mathrm{CH}_{3}\right)$ bend

1032 (C-O) stretch

2925 \& $2854\left(\mathrm{CH}_{2}\right)$ asymmetric \& symmetric stretch

$1721(\mathrm{C}=\mathrm{O})$

1647 \& $1274\left(\mathrm{NO}_{2}\right)$ asymmetric \& symmetric stretch

1155 asymmetric ring stretch

1065 (C-O) stretch

$830(\mathrm{~N}-\mathrm{O})$ stretch

749 (N-O) bend

2969 \& $2869\left(\mathrm{CH}_{3}\right)$ asymmetric \& symmetric stretch

2925 \& $2854\left(\mathrm{CH}_{2}\right)$ asymmetric \& symmetric stretch

$1770(\mathrm{C}=\mathrm{O})$

1594 \& 1605 doublet, aromatic ring stretch

1081,1015 \& 830 (1,4 disubstituted aromatic ring)

$3350_{\text {broad }}(\mathrm{OH})$ suggests degradation

2943 \& $2854\left(\mathrm{CH}_{3}\right)$ asymmetric stretch \& symmetric stretch

$2917\left(\mathrm{CH}_{2}\right)$ asymmetric stretch

$1714(\mathrm{C}=\mathrm{O})$ suggests degradation

$1620(C=C)$ stretch

1442 \& $1375\left(\mathrm{CH}_{3}\right)$ asymmetric \& symmetric bend

$1069_{\text {weak }}$ suggests degradation

$2925\left(\mathrm{CH}_{2}\right)$ stretch

$2861_{\text {shoulder }}(\mathrm{C}-\mathrm{H})$ stretch (phthalate plasticiser)

$1720(\mathrm{C}=\mathrm{O})$ (phthalate plasticiser)

1579 and 1602 doublet (phthalate plasticiser)

$1427\left(\mathrm{CH}_{2}\right)$ bend

$1255(\mathrm{C}-\mathrm{H})$ bend, in phase

961(C-C) stretch

693 (C-Cl) stretch

$3325(\mathrm{~N}-\mathrm{H})$ stretch

$2973(\mathrm{C}-\mathrm{H})$ stretch, asymmetric

$2865(\mathrm{C}-\mathrm{H})$ stretch, symmetric

$1725(C=0)$ stretch

1639 (OCONH) 
Table 2 Main ATR-FTIR absorption bands (Continued)

Polypropylene (HS 77, 400, 403, 416 \& 444)

Polyethylene (HS 80, 404, 417, 459 \& 463)
$1538(\mathrm{~N}-\mathrm{H})$ deformation

$1088(\mathrm{OCONH})$ in plane

2947 \& $2869\left(\mathrm{CH}_{3}\right)$ asymmetric \& symmetric stretch

2921 \& $2839\left(\mathrm{CH}_{2}\right)$ asymmetric \& symmetric stretch

1453 \& $1378\left(\mathrm{CH}_{3}\right)$ asymmetric \& symmetric bend

$1438\left(\mathrm{CH}_{2}\right)$ bend

1166 \& 996 indicative of isotactic form

2917 \& $2854\left(\mathrm{CH}_{2}\right)$ asymmetric \& symmetric stretch

$1470\left(\mathrm{CH}_{2}\right)$ bend

$1378\left(\mathrm{CH}_{3}\right)$ symmetric bend (low density only)

$719\left(\mathrm{CH}_{2}\right)$ rocking
(PU5) despite the fact that PU5, in particular, showed significant signs of degradation, such as discolouration and crumbling. All of the other samples PU2-4 looked unchanged from the unaged sample (PU1). When the replicate spectra were imported into Matlab, derivatised, normalised and mean-centred PCA was able to clearly differentiate the samples, as illustrated in Figure 5. This would suggest that it is possible to identify the early onset of degradation of polyurethane foam using PCA; this would not be possible by spectral matching using commercial or online databases. The unaged PU1 sample spectra were clustered together with a high PC1 score and zero PC2 score (see triangles at far RHS of the figure). Moving down along the PC1 axis, the next set of data that clustered together belonged to PU2 (stars), this sample was exposed in the chamber for $24 \mathrm{~h}$ but protected from light. Moving further down along the PC1 axis, PU3 data (squares) clustered together indicating that light does have an impact on the sample even after a $24 \mathrm{~h}$ exposure. Samples placed in the Weather-

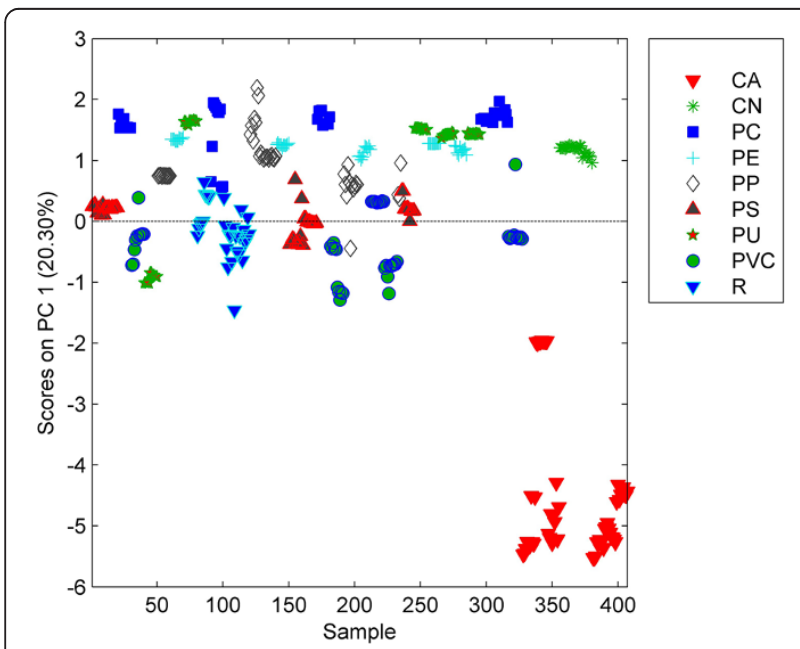

Figure 1 Scores plot for PC1.
Ometer for $144 \mathrm{~h}$ were easily distinguished from those aged for 24 h: Samples PU4 (diamonds) and PU5 (crosses) had negative PC1 scores whereas samples PU2 and PU3 had positive PC1 scores. Examination of the PC1 score values will permit differentiation between samples which have been thermally aged at $50 \% \mathrm{RH}$ for either 24 or $144 \mathrm{~h}$, indicating that a chemical difference had been imparted to samples with increased exposure time. Light ageing did not appear to affect the PU sample when an ageing time of $24 \mathrm{~h}$ was applied (no difference in PC2 score for PU2 or PU3). In contrast after the $144 \mathrm{~h}$ ageing time, spectra from the sample which was protected from light (PU4) clustered together in the lower left hand quadrant of the scores plot (negative PC2 scores) whereas the sample which was subjected to light (PU5) clustered together in the upper left hand quadrant of the scores plot. Using this model it would therefore be possible to determine whether unknown PU samples were 'fresh', thermally aged or photochemically aged by projecting its PCA result onto the PC1 versus PC2 scores plot.

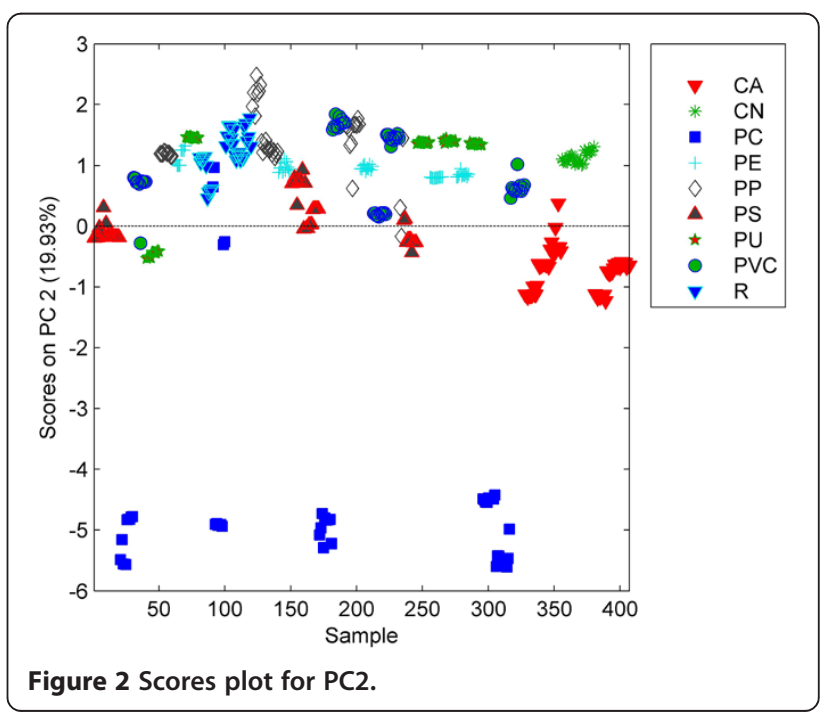




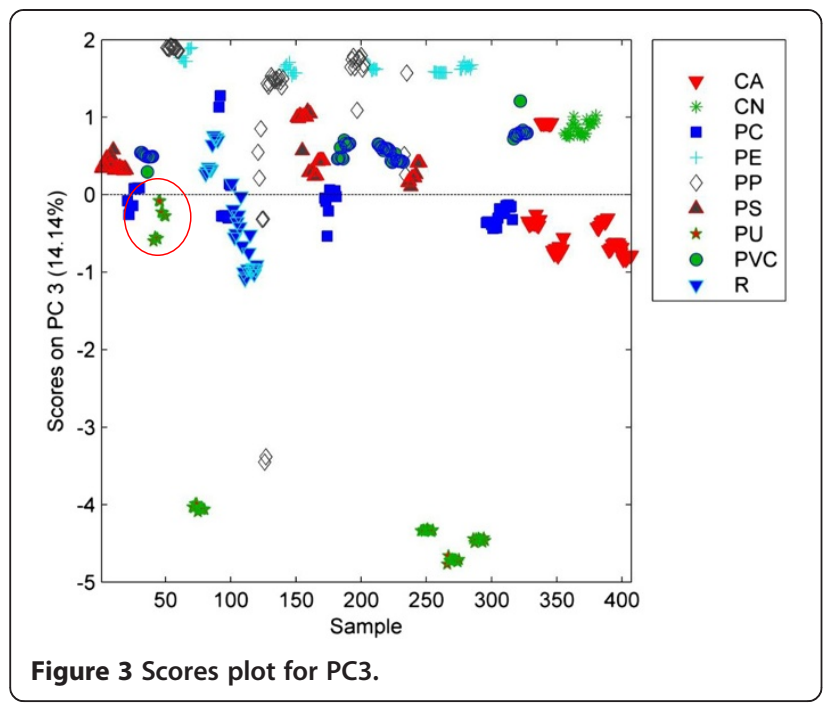

\section{Experimental}

\section{Details of instrumentation}

A transportable diamond crystal attenuated total reflectance-Fourier transform infrared (ATR-FTIR) spectrometer (Agilent Technologies 5500a) was used to collect spectra in the $650-4000 \mathrm{~cm}^{-1}$ region. The spectra were collected using Microlab PC software in absorbance mode using 128 scans at $8 \mathrm{~cm}^{-1}$ resolution. No sample preparation was required and polymers were directly analysed on the diamond window. Intimate contact of the sample with the crystal window was required to give good quality spectra; samples were clamped against the diamond window using a pressure clamp for solids. Samples were often irregularly shaped and ten spectra $(n=10)$ were recorded across the entire surface of the object under study. Spectra were processed with MATLAB version 7.13.0.564 (R2011b) (Mathworks Inc.,

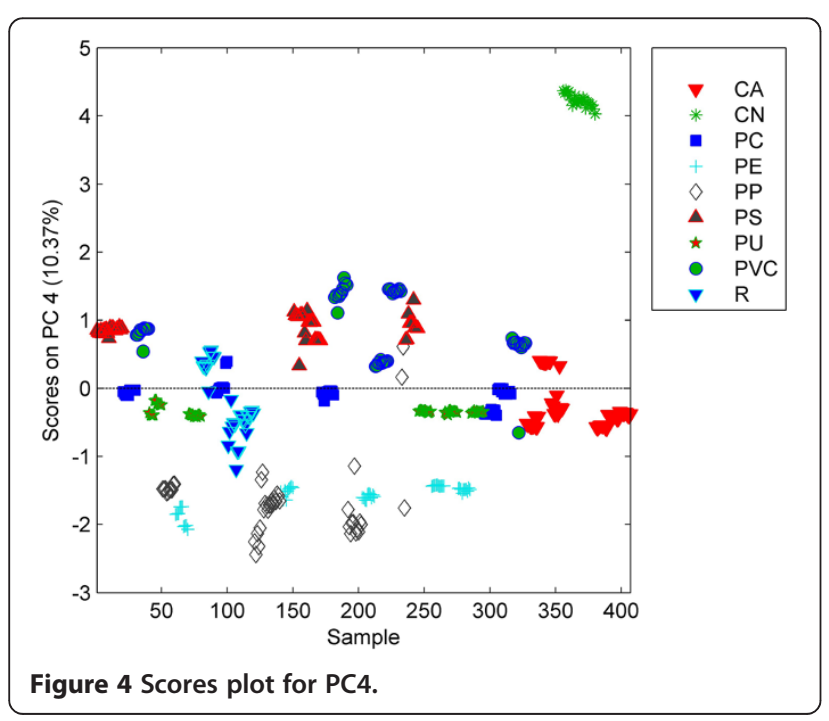

Table 3 Ageing conditions for PU sample HS464

\begin{tabular}{lcccc}
\hline Sample name & Temp $/{ }^{\circ} \mathbf{C}$ & RH / \% & Light exposure & Time / h \\
\hline PU 1 (ref) & - & - & - & - \\
PU 2 & 50 & 50 & No & 24 \\
PU 3 & 50 & 50 & Yes & 24 \\
PU 4 & 50 & 50 & No & 144 \\
PU5 & 50 & 50 & Yes & 144 \\
\hline
\end{tabular}

Natick, MA, USA) incorporating PLS_Toolbox version 6.7 (Eigenvector Research Inc., WA, USA). Data were derivatised (Savitzky Golay $1^{\text {st }}$ derivative filter with 13 points and a $2^{\text {nd }}$ order polynomial) to remove baseline offset, normalised to the largest peak and then mean centred prior to carrying out PCA. The pre-processing techniques used helped to reduce noise and emphasise any regions of spectral change.

\section{Principal component analysis (PCA)}

A method of determining correlations in spectral data sets is to use PCA which describes the data, not by wavenumber, but using a smaller number of 'latent' variables, called principal components (PCs). The PC's, obtained from the original data must reflect the underlying structure of the data, both in terms of the relationships between the different samples (objects) and the relationship between the different measurement variables (e.g. spectral wavenumber). Comparison of the samples' principal components will permit easy detection of correlations between samples and/or their original variables. When analysing PCA data, the eigenplot is first examined to determine the number of PCs that reflect the variation in the data. Those PCs are then further interrogated using, in this instance, scores plots to examine sample correlations. Samples with similar

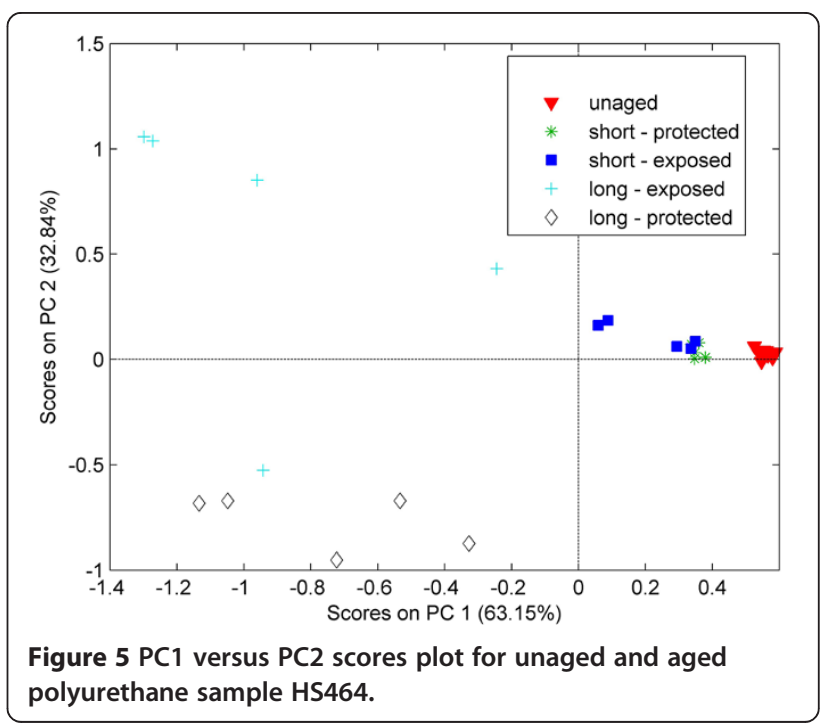


spectral features should cluster together in the scores plot where the PCs contain information on these spectral features.

\section{Accelerated ageing conditions}

Accelerated ageing was conducted on polyurethane sample HS464. Artificial ageing was conducted using an Atlas Ci4000 Weather-Ometer and the conditions used are given in Table 3. The xenon light source used had full spectrum from $200 \mathrm{~nm}$ to $750 \mathrm{~nm}$ with a CIRA inner, and a soda lime and float glass outer filter to provide a cut-off at $300 \mathrm{~nm}$. The irradiance measured at a wavelength of $420 \mathrm{~nm}$ was $1 \mathrm{Wm}^{-2}$ (approximately 0.4 $\mathrm{Wm}^{-2}$ at $340 \mathrm{~nm}$ ); samples PU2 and PU4 were protected from the light using an additional UV filter. The polyurethane fragments were attached to acid free conservation grade cardboard, mounted in brackets and hung inside the Weather-Ometer. After ageing, the samples were analysed using the same ATR-FTIR instrument and conditions outlined above and the spectra were compared to reference spectra collected from an unaged fragment of HS464.

\section{Conclusions}

ATR-FTIR spectroscopy was, once again, shown to be a suitable method of characterisation of unknown polymers commonly found in heritage collections. Here the spectra were interpreted by band assignment rather than using spectral matching via libraries. Polymer fragments were analysed without sample pre-treatment and were easily identified by visual examination of the collected spectra. The technique lends itself to the analysis of smaller polymer samples (due to the use of the pressure clamp) or polymer fragments. Care needs to be taken when 'softer' samples are analysed to ensure the imprint from the arm clamp is not visually apparent after sampling. It should also be noted that ATR-FTIR spectroscopy is a surface technique therefore caution must be used when analysing a sample which could comprise of polymer layers. Matching unknown samples to collected data was attempted using PCA rather than spectral libraries. It was possible to unambiguously determine samples that contained cellulose acetate, polycarbonate, polyurethane foam or cellulose nitrate; regardless of the age of the sample, its formulation or the presence of additives. More importantly, PCA was used to differentiate polyurethane samples that had been aged using thermalor photo-ageing treatment despite the inability to see visual changes in either the material or the collected spectra. This provides users with a tool to identify the early stages of polyurethane deterioration. Similar work is now being conducted on the other polymer family groups identified in this study.

\section{Additional files}

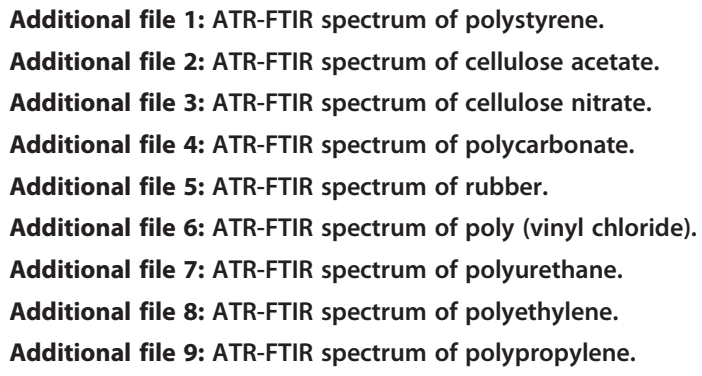

\section{Abbreviations}

ATR-FTIR: Attenuated total reflectance-Fourier transform infrared; VOC: Volatile organic compound; PCA: Principal component analysis; SPRA: Scottish Plastic and Rubber Association; CA: Cellulose acetate; CN: Cellulose nitrate; PC: Polycarbonate; PE: Polyethylene; PP: Polypropylene; PS: Polystyrene; PU: Polyurethane; PVC: Polyvinylchloride; R: Rubber.

\section{Competing interests}

The authors declare that they have no competing interests.

\section{Authors' contributions}

GM: Analysis and ageing of plastic samples, data interpretation and write article. LTG: design of experiments, data interpretation and article review. FF: design of experiments and article review. AN: Principal component analysis and article review. PTL: ATR-FTIR instrumentation and article review. All authors have read and approved the final manuscript.

\section{Acknowledgements}

The Science and Heritage Programme of the AHRC/EPSRC is gratefully acknowledged for the funding which supported this study. The Kluge Center and the Library of Congress are gratefully acknowledged for facilitating accelerated ageing and providing access to collections. Agilent Technologies is gratefully acknowledged for allowing access to their instrumentation. The British Museum, University College London and Edinburgh Napier University are acknowledged for the supply of some of the samples used in this study. The Royal Society is thanked for the award of a University Research Fellowship to AN.

\section{Author details}

'Department of Pure and Applied Chemistry, WestCHEM, University of Strathclyde, Glasgow G1 1XL, UK. '2 Library of Congress, Preservation, Research and Testing Division, 101 Independence Avenue, S.E, Washington, DC, USA. ${ }^{3}$ Agilent Technologies, 5 Lochside Avenue, Edinburgh Park, Edinburgh EH12 9DJ, UK.

Received: 5 June 2013 Accepted: 30 August 2013

Published: 11 September 2013

\section{References}

1. Coughlin M, Seeger AM: You collected what?! The risks and rewards of acquiring cellulose nitrate. In Proceedings of plastics- looking to the future and learning from the past. Edited by Keneghan B, Egan L. London: Archetype Publications; 2007:119-124

2. Reilly JA: Celluloid objects: their chemistry and preservation. J Am Inst Conserv 1991, 30:145-162.

3. Shashoua Y: Conservation of plastics: materials science, degradation and preservation. US: Butterworth Heinemann; 2008.

4. Williamson $\mathrm{CJ}$ : In Polymers in conservation, 150 years of plastics degradation. Edited by Allen NS, Edge M, Horie CV. Cambridge: Royal Society of Chemistry; 1991:1-13.

5. Then E, Oakley V: A survey of plastic objects at The Victoria and Albert Museum. V\&A Conser J 1993, 06:11-14.

6. Shashoua Y, Ward C: Plastics: modern resins with ageing problems. In Proceedings of SSCR 2nd Resins Conference, Resins-Ancient and Modern. Edited 
by Wright MM, Townsend JH. Edinburgh: Scottish Society for Conservation and Restoration; 1995:33-37.

7. Keneghan B: In Preservation of plastic artefacts in museum collections. Edited by Lavédrine B, Fournier A, Martin G. Belgium: CTHS; 2012.

8. Watanabe M, Nakata C, Wu W, Kawamoto K, Noma Y: Characterisation of semi-volatile organic compounds emitted during heating of nitrogencontaining plastics at low temperature. Chemosphere 2007, 68:2063-2072.

9. van Oosten TB: A survey of problems with 'early' plastics. In Contribution to conservation. Edited by Mosk JA, Tennent NH. London: James and James; 2002:87-95.

10. Blank S: An introduction to plastics and rubbers in collections. Stud Conserv 1990, 35:53-63.

11. Hatchfield PB: Pollutants in the museum environment- practical strategies for problem solving in design, exhibition and storage. UK: Archetype Publications; 2002.

12. Littlejohn D, Pethrick RA, Quye A, Ballany JM: Investigation of the degradation of cellulose acetate museum objects. Jof Polymer Degrad and Stab 2013, 98:416-424.

13. Ward C, Shashoua Y: Interventive conservation treatments for plastics and rubber artefacts in The British Museum. In Proceedings of 12th Triennial Meeting ICOM committee for conservation. Edited by Bridgland J. London: James and James; 1999:888-893.

14. Coates J: Interpretation of infrared spectra- a practical approach. In Encyclopedia of analytical chemistry. Edited by Meyers RA. Chichester: John Wiley \& Sons Ltd; 2000

15. Connors SA, Murray A, Paroli RM, Delgado AH, Irwin JD: Spectroscopic investigation of the degradation of vulcanised natural rubber museum artifacts. In Historic textiles, papers and polymers in museums- ACS symposium, Volume 779. Edited by Cardamone JM, Baker MT. Washington DC: American Chemical Society; 2001:166-184.

16. Thickett D, Richardson E: Preventative conservation research for plastics on open display. In Proceedings of plastics- looking at the future and learning from the past. Edited by Keneghan B, Egan L. London: Archetype Publications; 2008:89-96.

17. Stromberg RR, Straus S, Achhammer BG: Infrared spectra of thermally degraded poly (vinyl chloride). J Res Natl Bur Stand 1958, 60:147-152.

18. Bower DI, Maddams WF: The vibrational spectroscopy of polymers. Cambridge: Cambridge University Press; 1989.

19. Kraus RG, Emmons ED, Thomson JS, Covington AM: Infrared absorption spectroscopy of polycarbonate at high pressure. J Polym Sci B 2008, 46:734-742

20. Stuart BH: Analytical techniques in materials conservation. Chichester: John Wiley and Sons Ltd; 2007.

21. Gudim LI, Klimenko PL: Infrared spectra of polyurethanes in the near infrared region. J App/ Spectrosc 1972, 16:685-686.

22. van Oosten TB: Crystals and crazes: degradation in plastics due to microclimates. In Plastics in art: history, technology, preservation. Edited by van Oosten TB, Shahoua Y, Waentig F. Munich: Siegel; 2002

23. Price BA, Malenka S, Sutherland K, Lins A, Carlson JH: Naum Gabo's construction in space: two cones- history and materials. In Proceedings of plastics-looking to the future and learning from the past. Edited by Keneghan B, Egan L. London: Archetype Publications; 2008:81-88.

24. Larkin PJ: IR and Raman spectroscopy-principles and spectral interpretation. USA: Elsevier; 2011

25. Shashoua Y, Bradley SM, Daniels VD: Degradation of cellulose nitrate adhesive. Stud Conserv 1992, 37:113-119.

26. Shashoua Y: In Research into plastics and rubbers in the British Museum Edited by Tennent NH. James and James Science; 1993:44-47.

27. Stewart RA: Analytical studies of the degradation of cellulose nitrate artefacts. PhD Thesis. University of Strathclyde; 1997.

28. Beltrán M, García JC, Marcilla A: Infrared spectral changes in PVC and plasticized PVC during gelation and fusion. Eur Polym J 1997, 33:453-462.

29. Shashoua Y: Effect of indoor climate on the rate and degradation mechanism of plasticized poly (vinyl chloride). Degrad Stab 2003, 81:29-36.
30. Nor HM, Ebdon JR: Ozonolysis of natural rubber in chloroform- Part 1. A study by GPC and FTIR spectroscopy. Polymer 2000, 41:2359-2365.

31. Grant IJ, Ward IM: The infrared spectrum of syndiotactic polypropylene. Polymer 1965, 6:223-230

32. Luongo JP: Infrared study of polypropylene. J App/ Polym Sci 1960, $3: 257-374$

doi:10.1186/2050-7445-1-28

Cite this article as: Mitchell et al:: Assessment of historical polymers using attenuated total reflectance-Fourier transform infra-red spectroscopy with principal component analysis. Heritage Science 2013 1:28.

\section{Publish with ChemistryCentral and every scientist can read your work free of charge \\ "Open access provides opportunities to our colleagues in other parts of the globe, by allowing anyone to view the content free of charge." \\ W. Jeffery Hurst, The Hershey Company.}

- available free of charge to the entire scientific community

- peer reviewed and published immediately upon acceptance

- cited in PubMed and archived on PubMed Central

- yours - you keep the copyright

Submit your manuscript here

http://www.chemistrycentral.com/manuscript/<smiles>c1ccccc1</smiles>

Chemistry Central 